University of Pennsylvania Carey Law School

Penn Law: Legal Scholarship Repository

Faculty Scholarship at Penn Law

2009

\title{
A Right to Bear Firearms but Not to Use Them? Defensive Force Rules and the Increasing Effectiveness of Non-Lethal Weapons
}

Paul H. Robinson

University of Pennsylvania Carey Law School

Follow this and additional works at: https://scholarship.law.upenn.edu/faculty_scholarship

Part of the Criminal Law Commons, Public Law and Legal Theory Commons, Science and Technology Law Commons, and the Second Amendment Commons

\section{Repository Citation}

Robinson, Paul H., "A Right to Bear Firearms but Not to Use Them? Defensive Force Rules and the Increasing Effectiveness of Non-Lethal Weapons" (2009). Faculty Scholarship at Penn Law. 224. https://scholarship.law.upenn.edu/faculty_scholarship/224

This Article is brought to you for free and open access by Penn Law: Legal Scholarship Repository. It has been accepted for inclusion in Faculty Scholarship at Penn Law by an authorized administrator of Penn Law: Legal Scholarship Repository. For more information, please contact PennlawIR@law.upenn.edu. 


\title{
ESSAY
}

\section{A RIGHT TO BEAR FIREARMS BUT NOT TO USE THEM? DEFENSIVE FORCE RULES AND THE INCREASING EFFECTIVENESS OF NON-LETHAL WEAPONS}

\author{
PAUl H. ROBinSON
}

INTRODUCTION

I. EXISTING RULES ON SELF-DEFENSE

II. EXISTING AND COMING NON-LETHAL WEAPONS

III. NON-LETHAL WEAPONS AND THE NECESSARY FORCE REQUIREMENT: MAKING FIREARM USE IN DEFENSE UNLAWFUL? ..... 256

A. Comparing the Defensive Effectiveness of Firearms and NonLethal Weapons.

B. Allocating Risk Between Attacker and Defender.

C. Creating the Conditions that Cause the Need for Excessive Force: The T1-T2 Analysis.

IV. NON-LETHAL WEAPONS AND THE PROPORTIONALITY REQUIREMENT: AUTHORIZING COWBOYS?

A. Universal Versus Two-Category Proportionality Requirement .. 261

B. Cowboys and the Universal Proportionality Requirement ...........2262

C. Cowboy Chaos or Full Vindication of Rights?............................... 263

CONCLUSION.

Under existing American law, advances in the effectiveness and availability of non-lethal weapons may increasingly undermine a right to use a firearm for defense because the choice to use a firearm for protection is increasingly a choice to use more force than is necessary. Ironically, the greatest practical effect of the Supreme Court's interpretation of the Second Amendment in District of Columbia v. Heller may be to invalidate statutes that limit the use of non-lethal weapons and, thereby, to ultimately undermine the right of firearm use.

While some might worry one's right to use defensive force is being eroded by these developments, the real concern may be the reverse: the technical advances combined with current law may promote a culture of non-lethal weapon "cowboys," in which non-lethal force is authorized in situations where no force would be used today.

\footnotetext{
* Colin S. Diver Professor of Law, University of Pennsylvania.
} 


\section{INTRODUCTION}

Much has been made of the Supreme Court's recent, narrowly decided opinion in District of Columbia $v$. Heller, ${ }^{1}$ which holds the Second Amendment gives citizens a right to keep a firearm at home for their personal use. ${ }^{2}$ Its discussion revolves around one's ability to defend oneself in case of "confrontation," 3 and some herald the decision as a significant victory for a citizen's right to use firearms in self-defense ${ }^{4}$ It is the criminal law's defensive force rules in the fifty-two American jurisdictions, however, not the Second Amendment nor anything said in Heller, that govern the use of defensive force. And those rules will increasingly limit the law's authorization of firearm use for defense. This increased limitation derives from the development of increasingly effective non-lethal weapons, which will make the choice to use a lethal firearm in defense a choice to use greater force than is necessary, in violation of existing law. In the long run, the Heller opinion may have little practical importance for gun owners. While it may give special constitutional protection to collectors of gunpowder technology, it may have little effect on the right to use a firearm in defense. ${ }^{5}$

Indeed, the greatest practical significance of Heller may arise from the fact that its logic and language seem to suggest a right to bear non-lethal weapons. Heller seems to suggest the Second Amendment creates a right to bear weapons "not specifically designed for military use and . . not employed in a military capacity," 6 but not weapons that are "dangerous and unusual." " That right would seem to include the increasingly common non-lethal weapons, such as Tasers. ${ }^{8}$ Yet some states permit the possession of lethal firearms but prohibit the possession of many non-lethal weapons. ${ }^{9}$ This Essay argues that

1 128 S. Ct. 2783 (2008).

${ }^{2}$ Id. at 2799.

${ }^{3}$ Id. at 2797.

4 See, e.g., Brian Doherty, Op-Ed., The Supreme Court Gun Fight; It's Not Over by a Long Shot, L.A. TimES, June 27, 2008, at A27 ("[Heller made] a strong statement about our right to self-defense and safety."); Bill Mears, High Court Strikes Down Gun Ban, CNN.com, June 26, 2008, http://www.cnn.com/2008/US/06/26/scotus.guns (stating that respondent Dick Heller commented, "I'm very happy that I am now able to defend myself and my household in my own home.").

5 These arguments were originally made in Paul H. Robinson, Op-Ed., Shoot to Stun, N.Y. TIMES, July 2, 2008, at A19.

${ }^{6} \mathrm{Heller}, 128 \mathrm{~S}$. Ct. at 2791.

${ }^{7}$ Id. at 2817.

${ }^{8}$ Taser is a trademark used for a high-voltage stun gun manufactured by TASER International, Inc. It is a well-known stun gun marketed to both law enforcement and ordinary consumers. See TASER, http://www.taser.com (last visited Nov. 4, 2008).

9 See, e.g., Haw. Rev. Stat. AnN. \$134-16 (LexisNexis 2006); Mass. Gen. Laws ch. $140, \S 131$ J (2006); N.J. STAT. ANN. $§ 2$ C:39-3h (West 2005); N.Y. PENAL LaW $\S 265.01$ 
as non-lethal weapons become more available, the authority to use firearms in defense diminishes. Thus, ironically, the greatest practical effect of the Supreme Court's interpretation of the Second Amendment in Heller may be its invalidation of statutes barring the possession of non-lethal weapons, which then ultimately undermines the right to use a firearm in defense.

\section{EXISTING RULES ON SELF-DEFENSE}

The current defensive force laws set two kinds of limits on the force that may be used in defense: a necessary force limitation and a proportionality limitation. ${ }^{10}$ The necessary force limitation provides that one may use no more force than is necessary for effective defense, nor use it before the time when it is necessary. ${ }^{11}$ For example, the Model Penal Code permits the use of only that amount of force "immediately necessary" for defense. ${ }^{12}$ The proportionality limitation works differently; it authorizes only the use of force that is proportionate to the harm threatened. ${ }^{13}$ For example, the Model Penal Code restricts the use of "deadly force," which includes the use of a firearm, to situations in which death or serious bodily injury is threatened. ${ }^{14}$

These two limitations have an independent effect. One's use of force could meet the necessary force requirement but not the proportionality requirement. Consider a paraplegic who can only defend himself against someone kicking him in the shins in an elevator by shooting the person. If the attacker refuses the paraplegic's requests to stop kicking, shooting the attacker would be necessary but not proportionate, and thus unauthorized. Alternatively, force might meet the proportionality requirement but not the necessary force requirement. Consider a person with a tenth degree karate black belt who shoots a knife-wielding attacker when he could instead safely and easily disarm the attacker with an expert kick. The shooting may be proportional but not necessary, and thus unauthorized.

As Parts III and IV make clear, these essentially universal requirements for the lawful use of defensive force have serious implications for firearm use, especially in light of the recent dramatic advances in non-lethal weapon technologies.

(McKinney 2000); R.I. GEN. LAWS $§ 11-47-42$ (2002); WIS. STAT. ANN. $§ 941.295$ (West 2005).

${ }^{10}$ See Paul H. Robinson, Criminal Law $\S \S 8.2-8.4$ (1997).

1 See id. $\S 8.4$, at 442 .

12 Model Penal Code $\$ 3.04$ (1) (Proposed Official Draft 1962).

${ }_{13}$ See Robinson, supra note $10, \S 8.4$, at 443-45.

${ }^{14}$ Model Penal Code $\$ 3.04(2)(b)$. 


\section{EXISTING AND COMING NON-LETHAL WEAPONS}

Consider a brief glimpse of the non-lethal weapons either on the market or in working prototype. Chemical sprays, such as mace or pepper spray, are common today. ${ }^{15}$ They can disable attackers, but only at close range, and they sometimes have limited effectiveness. ${ }^{16}$ Entanglers are also available, but similarly have serious limitations because they are too bulky. ${ }^{17}$ Low-kinetic impact projectiles can provide a more effective alternative. Many of these can be used in current firearms but typically do not have the long stand-off distance of normal firearm ammunition, ${ }^{18}$ and have a limited ability to stop an attacker because they depend upon the attacker responding to pain or becoming confused. ${ }^{19}$

15 See Joel H. Garner \& Christopher D. Maxwell, Understanding the Prevalence ani) Severity of Force Used by and Against the Police: Executive Summary 1 (2002), available at http://www.ncjrs.gov/pdffiles1/nij/grants/196693.pdf.

16 See Nat'l Sec. Research, Inc., Department of Defense Non-Lethal Weapons ANi) Equipment ReView: A RESEARCh Guide FOR CiVIL LAW ENFORCEMENT and CORRECTIONS C-9 (2002), available at http://www.ncjrs.gov/pdffiles1/nij/grants/200516.pdf (showing that one weapon designed for individual use, the MK-4 Individual Live Pepper Spray, has a range of up to only fifteen feet in a target-specific stream); U.S. ARMY, TACTICAL EMPLOYMENT OF NONLETHAL WEAPONS A-3 (2003) [hereinafter ARMY, NONLETHAL WEAPONS] (describing the range as only twelve feet).

17 Brian RAppert, Non-Lethal Weapons as Legitimizing forces: Technology, Pol.itics and the MANAgement Of CONFlict 44 (2003); U.S. Air Force INST. FOR NAT'L SeC. Stud., Nonlethal Weapons: Terms And ReferenCES 14 (Robert J. Bunker ed., 1997) [hereinafter USAF INSS, NONLETHAL WEAPONS], http://www.usafa.af.mil/df/inss/OCP/ocp15.pdf (describing common entanglers, including nets that constrain an individual). Various net systems include guns that shoot nets designed for ensnaring single individuals. NEIL DAVISON \& NICK LEWER, BRADFORD NON-LETHAL WEAPONS RESEARCH PROJECT $20 \quad$ (2003), http://www.brad.ac.uk/acad/nlw/research_reports/docs/BNLWRPResearchReportNo4_Dec0 3.pdf. Also available are large, long-range nets designed to capture three or four individuals, "sticky" nets that make it more difficult for those ensnared to free themselves, electrified nets that deliver shocks, and nets detonated from mines. JOHN B. ALEXANDER,

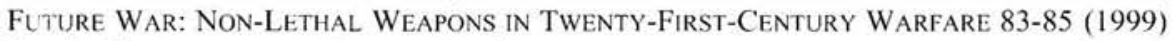
[hereinafter ALEXANDER, FUTURE WAR].

18 Rubber projectiles have a range of up to thirty meters. NAT'L RESFARCH COUNCIL, THI: NAT'L ACADEMIES, AN ASSESSMENT OF NON-Lethal WEAPONS SCIENCE AND TFCHNOLOGY 25 (2003) [hereinafter NRC, ASSESSMENT]. The forty-millimeter foam rubber baton cartridge is best used from twenty to forty feet and can be fatal under twenty feet; the twelve-gauge rubber Fin Stabilized Cartridge has a range of ten to twenty meters; and sponge grenades can knock down an individual from up to fifty meters. ARMY, NONLETHAL. WEAPONS, supra note 16 , at B-4 to -14 . The working range of current hollow rubber projectiles is from five to seventy-five feet, and plastic bullets have an effective range of thirty to sixty-five yards. USAF INSS, NONLETHAL WEAPONS, supra note 17, at 20-24.

${ }^{19}$ NRC, ASSESSMENT, supra note 18, at 25. 
Tasers and other such electrical shock weapons are likely to provide the most effective protection of the currently available non-lethal devices. Their disabling effect upon contact is typically excellent: they induce immediate muscle spasm operating at an autonomic level without regard to how determined an attacker may be. ${ }^{20}$ Further, the effective disabling zone on an attacker's body is large - any good contact by a Taser will instantly disable. ${ }^{21}$ Because they commonly come with a laser sight, they also are easy to aim. ${ }^{22}$ On the other hand, most Tasers do not have the second shot capability needed if the first shot misses, although they can be quickly reloaded. ${ }^{23}$

Whatever the current state of non-lethal weapons, it is clear the market for such devices is strong and is driving a development process of constant improvements. ${ }^{24}$ More importantly, new forms of non-lethal weapons now in prototype promise to go far beyond the effectiveness of Taser technology. Light lasers instantly blind an attacker for a certain period. ${ }^{25}$ Low-energy beams and microwave technology instantly disable a person by producing the sensation of burning pain but with no lasting effect. ${ }^{26}$ These weapons have an

20 John B. Alexander, Winning the War: Advanced Weapons, Strategies, AND CONCEPTS FOR THE POST-9/11 WORLD 18 (2003) [hereinafter ALEXANDER, WINNING THE WAR].

21 See Alexander, Future War, supra note 17, at 67 ("[Taser] delivers a 25,000-volt shock that causes loss of neuromuscular control. The affected person normally falls to the ground due to the inability to operate his or her legs.").

${ }^{22} I d$.

${ }^{23}$ See TASER INT'L, INC., TASER X26C OPERATING MANUAL 15 (2007), available at http://taser.com/SiteCollectionDocuments/Downloads/MK-INST-X26C-001 REV A X26C Manual.pdf ("The TASER Cartridges for the X26C are specifically designed so there is no 'up' or 'down' position - enabling you to quickly reload one in a stressful situation without worrying about putting it in upside down."). Additionally, once a person is shot, the Taser trigger can be used to apply additional shocks as needed. See ALEXANDER, FUTURE WAR, supra note 17 , at 67.

${ }^{24}$ See, e.g., ALEXANDER, WINNING THE WAR, supra note 20, at 11.

${ }^{25}$ See Eva D. Blaylock, New Technology 'Dazzles' Aggressors, AIR ForCE LinK, Nov. 2, 2005, http://www.af.mil/news/story.asp?storyID=123012699. Many laser technologies are completely or nearly developed and include: flares; the Cobra, a "30-pound hand-held laser weapon used to damage enemy sensors and human eyes"; the Dazer, a "[b]attery operated 20,000 candlepower 'flashlight,"” that attacks sensors and night vision devices; the Dazzle Rifle, a laser beam designed to disorient the target; high intensity hydrogen-chloride lights; the MK 1 illuminating grenade, which produces " 55,000 candlepower for twenty-five seconds" (used in Vietnam); isotropic radiators, which illuminate with "laser-bright intensity"; the eye safe low-energy laser, which produces a glare strong enough to temporarily delay and disorient an adversary in a range of several hundred meters, and is powered by six rechargeable AA batteries; and a stroboscopic device, which causes flashing like a strobe light. USAF INSS, NONLETHAL WEAPONS, supra note 17, at 18-21.

${ }^{26}$ See, e.g., NRC, ASSESSMENT, supra note 18, at 30; US Military Unveils Heat Ray Gun, BBC NEws, Jan. 25, 2007, http://news.bbc.co.uk/2/hi/americas/6297149.stm. 
important advantage over weapons like firearms or Tasers; by firing a continuous beam or series of pulses, they make it easy to hit a target. ${ }^{27}$

\section{NON-LETHAL WEAPONS AND THE NECESSARY ForCE REQUiREMENT: MAKING FIREARM USE IN DEFENSE UNLAWFUL?}

Given the existing law, using a firearm in self-defense poses an obvious legal difficulty: if one can defend oneself as effectively with a non-lethal weapon, then the use of a lethal firearm is not "necessary" and is therefore unjustified and unlawful. The evidence suggests current non-lethal weapons offer as effective protection as firearms. ${ }^{28}$ And, even if some would argue that point now, the continually increasing effectiveness of non-lethal weapons means the debate will fade altogether as technical advances accumulate.

Beyond disputing the claim that non-lethal weapons are more effective than firearms, one might make two sorts of counter-arguments in support of the continued use of firearms, at least in the short term: (1) even if non-lethal weapons can protect, because they cause less damage and are less likely to kill an offender, this means they necessarily create some risk to the defender, which ought not be tolerated simply to reduce the risk of death of a lawbreaker; and (2) most defenders will not have a non-lethal weapon handy at the time of the attack, so their lethal firearms are the least harmful means of defense available.

\section{A. Comparing the Defensive Effectiveness of Firearms and Non-Lethal Weapons}

One might attempt to argue that currently available non-lethal weapons, while effective in many ways, are not yet in all respects equally effective in defense compared to lethal firearms. One could argue that "instant killing power" is necessarily the best defense, for only in this way can you be sure an attacker will not get off a shot or get close with his knife attack, etc. However, to be guaranteed an instantly disabling shot with a firearm, one must hit the target either in a business-card-size area between the eyes or at the top of the spine at the back of the neck. ${ }^{29}$ Anything less than this will produce an injured attacker but one who may take some time to die. ${ }^{30}$ In contrast, the new generation of Tasers can hit anywhere on a person's body to disable instantly through involuntary muscle spasm. ${ }^{31}$ Studies suggest firearms typically have

27. See sources cited supra note 25 .

28 See infra Part III.A.

29 See Urey W. Patrick, FBI, Handgun Wounding Factors and EFfectiveness 8 (1989).

36 $I d$.

${ }^{31}$ See Taser UK, Frequently Asked Questions, http://www.taser.co.uk/index.php?zone=public\&page=faq (last visited Oct. 20, 2008) 
only a fifty to seventy-five percent one-shot stop rate, ${ }^{32}$ while Tasers have a ninety-three percent rate. ${ }^{33}$

One might argue guns provide an advantage because they can be used at a greater distance. Currently, Tasers are available for use at ranges up to fifteen feet for consumers and twenty-one feet for law enforcement and the military. ${ }^{34}$ But the shorter striking distance for Tasers may have little significance. Most confrontations occur within ten feet ${ }^{35}$ - well within the effective range of Tasers - and firearm accuracy decreases drastically with distance even for trained individuals. ${ }^{36}$ Further, the legal limitations on self-defense typically do not allow use of force at a distance. Defensive force is considered "immediately necessary" only when the defender can wait no longer, commonly when the threat is imminent. ${ }^{37}$

No matter what one thinks of the comparison of firearms and current Tasers, the debate will fade with the foreseeable advances in all manner of non-lethal weapons. The time will come when the superiority of non-firearm

("Unlike other weapons it is not critical for the probes to contact any specific part of the body to be effective. Indeed it is sufficient for the probes to lodge in the clothing.").

${ }^{32}$ Here, I am defining a "one-shot stop" rate as: (1) a single hit to anywhere on the body not counting the head, neck or extremities, (2) when the subject stops shooting or striking blows if that was what he was doing, and (3) runs no more than ten feet before collapsing. See, e.g., Evan P. Marshall \& Edwin J. Sanow, Handgun Stopping Power: The Definitive StUdy 43 (1992). The rate varies with the caliber of the gun and the grain of the bullet. Id. at 211-14.

${ }^{33}$ R.T. Wyant, The Advanced TASER M26, X26: Forensic Considerations, 36 AFTE J. 267,267 (2004)

${ }^{34} \mathrm{Id}$. The company that makes Tasers seeks to have police retain a weapons superiority over citizens. Telephone Interview with Steve Tuttle, Vice-President of Communications, Taser International, Inc. (July 1, 2008).

${ }^{35}$ Cf. Thomas J. Aveni, The Police Policy Studies Council, Officer-Involved SHOOTINGS: WHAT WE DIDN'T KNOW HAS HURT US 7 (2002), available at http://www.theppsc.org/Staff_Views/Aveni/OIS.pdf (stating $69 \%$ of shooting incidents involving NYPD Officers between 1994 and 2000 occurred in the $0-2$ yard range, $19 \%$ in the $3-7$ yard range, $6 \%$ in the $8-15$ yard range, $2 \%$ in the $16-25$ yard range, $1 \%$ in the $25+$ yard range, and $2 \%$ in an unknown range); see also TOM PERRONI, PERRONI's TACTICAL TRAINING ACADEMY, HANDGUN STOPPING POWER 1, http://www.perronitactical.com/uploads/HandgunStoppingPoweredited.doc (last visited Nov. 5, 2008) ("Most shootings involving police officers and civilian concealed carry permit holders happen at a distance of less than ten feet with average distance at three feet.").

${ }^{36}$ For example, the NYPD Hit Ratios By Distance are as follows: $38 \%$ in the $0-2$ yard range, $17 \%$ in the $3-7$ yard range, $9 \%$ in the $8-15$ yard range, $8 \%$ in the $16-25$ yard range, $4 \%$ in the $25+$ yard range, and $2 \%$ in an unknown range. AVENI, supra note 35 , at 7 .

${ }^{37}$ In fact, many jurisdictions have explicitly retained the common law's "imminent threat requirement." See RoBINSON, supra note 10, $\$ 8.2$, at 410-12. 
technologies will be undebatable, when all will agree that non-lethal weapons are more effective, more accurate, and safer than conventional firearms.

\section{B. Allocating Risk Between Attacker and Defender}

But assume for the sake of argument that the defensive superiority of nonfirearm technology is not clear, and assume the lethality of firearms does itself provide a special and irreplaceable advantage for a defender. It still does not follow that the choice of a somewhat more effective lethal firearm over a somewhat less effective non-lethal weapon would be justified under current law. In the balance of defender safety against attacker injury, the law does not authorize the allocation of all risk to the attacker and away from the defender. ${ }^{38}$

Consider, for example, the temporal aspect of the necessity requirement. Assume a person makes credible threats against another person that, if implemented, would justify the use of defensive force. Because the intended victim does not know when the attacker will carry out the threats, the safest course for the defender would simply be to use force against the threatener at the time when it would be most effective and could be done with the least risk. Requiring the intended victim to wait until the attack is imminent creates added risk to the victim, for the attacker may pick the time when the intended victim is most vulnerable and the attacker is in the position of greatest advantage. Yet, the law does not allow the victim to defend himself in this most effective way. Instead, it requires the victim to suffer the risk by requiring that he wait until the attack is imminent or until defensive force is immediately necessary. ${ }^{39}$

Why should the law do such a thing? Because the law values all lives, even that of a law-breaker. The law judges it to be better for the victim to suffer the added risk, as unfortunate as that is, in hopes the attacker will change his mind and desist, or the police or others will intervene to prevent the attack. One may think this unfair: it gives "rights" of a sort to a law-breaker threatening a victim. But it is this recognition of the value of human life, even that of a lawbreaker, that has come to mark a civilized society. Note that the proportionality requirement in the use of defensive force has the same effect. ${ }^{40}$ It tells the paraplegic he must simply suffer the kicks in the elevator if his only means of preventing them is to shoot the kicker.

${ }^{38}$ See supra notes 10-14 and accompanying text.

39 The common law required that the attack be "imminent," but the Model Penal Code shifts the requirement to one that the use of defensive force be "immediately necessary." MOdel Penal CODE $\$ 3.04$ (1) (Proposed Official Draft 1962). For further discussion of the triggering conditions and the requirements that the use of defensive force be both necessary in time and the minimum amount of force necessary to defend against the threat, see RoBINSON, supra note $10, \S 8.4$, at 437,442 .

40) See supra notes 13-14 and accompanying text. 
The same balancing of interests applies to the choice of weapons even if non-lethal weapons were not yet as fully effective as firearms. Killing an attacker with a lethal firearm, rather than just disabling him temporarily with a non-lethal weapon, may be judged an uncivilized balance if the benefit bought by killing the attacker is only a minor reduction in the risk the defender will be injured. Keep in mind that there are a host of factors other than the "stopping power" of his weapon that will affect a defender's safety. ${ }^{41}$ In the larger scheme, lethality of the victim's weapon may provide a trivial improvement to defender safety at a dramatically greater risk of death to the attacker.

\section{Creating the Conditions that Cause the Need for Excessive Force: The T1-T2 Analysis}

A defender might argue that if he had a non-lethal weapon available, he would have been happy to use it, but he had none handy. This argument will certainly be available for most defenders given the relative rate of ownership of guns as compared to ownership of non-lethal weapons. The firearm the defender does have, he can argue, was the least harmful means of defense available to him at the time he needed to defend himself (i.e., Time 2, or "T2"). But will the law ignore the fact that at some earlier time (i.e., Time 1, or "T1") the defender made a choice - to buy last year, or to take with him that morning - to have a lethal rather than a non-lethal weapon? Not likely.

Consider the case of the person who sets a fire which threatens a town, and then burns a firebreak in his enemy's cornfield to save the town. Will the law give him a defense to the property destruction because at T2 his burning was necessary, even though it was by his own earlier action - at $\mathrm{T} 1$, when he set the fire - that he was forced at T2 to burn the field? Current law will give him no defense. ${ }^{42}$

${ }^{41}$ Two major factors are: proper training and the circumstances surrounding the incident. See generally MARSHALL \& SANOW, supra note 32 (discussing various examples of circumstances surrounding shooting incidents and effects on stopping power). These two factors often go hand-in-hand. However, current training methods are not effective and thus have little effect on the street. Shooting at paper targets is unrealistic and causes shooters to adapt to that situation instead of real situations, such as being charged by a moving human target in the area of innocent bystanders. See Nancy Marion, Police Academy Training: Are We Teaching Recruits What They Need to Know?, 21 Policing InT'L J. Police StrategY \& MGMT. 54, 66-68 (1998). Circumstances surrounding the incident also impact defender safety. See Nat'l Research Council, Firearms and Violence: A Critical Review 21418 (Charles F. Wellford et al. eds., 2005) (showing protection technology - such as locking devices - present on the weaponry, child access prevention laws, and the age of the firearm user all affect weapon lethality).

42 See, e.g., Model Penal CodE $§ 3.02$ (2) (Proposed Official Draft 1962). I have argued elsewhere that current law is wrong in its treatment of these kinds of situations, in which a person causes the conditions of his own defense. See generally Paul H. Robinson, Causing the Conditions of One's Own Defense: A Study in the Limits of Theory in Criminal Law 
To put the situation in the self-defense context, assume you know another person is boiling mad at you and expect he will attack you if you enter his local bar. You head for the bar and as you leave the house, you choose to take your .357 Magnum instead of your equally effective non-lethal weapon. When you kill him in necessary self-defense, should you get the defense even though you could have avoided the death by picking the non-lethal weapon? Presumably the law should and would say "no defense." The killing might have been necessary under the conditions at T2, but at T1 you could have made a choice that would have avoided the killing.

Of course, people today do not have the lethal and non-lethal weapons sitting at home from which to choose. But as effective non-lethal weapons become more available, it will be harder for people to claim they did not have that choice when they are at the store buying a weapon for self-protection. The purchase of a hunting rifle by a hunter cannot be faulted, but the purchase of a firearm for self-defense, if an equally or more effective non-lethal weapon is available, reflects a choice to use greater force than is necessary.

\section{NON-LETHAL WEAPONS AND THE PROPORTIONALITY REQUIREMENT: AUTHORIZING COWBOYS?}

Some may disapprove of the shift to non-lethal weapons that the current law's necessary force limitation promotes. One may worry it erodes a person's right to defend against aggressors. But there is reason to believe the real concern may be of the reverse sort: the shift to an era of non-lethal weapons may bring on an era of too much use of defensive force rather than too little. The technical advances combined with current law might promote a culture of non-lethal weapon "cowboys," in which non-lethal force is used in situations where no force would be used today.

A world in which most defenders use non-lethal weapons would be a world of fewer deaths, but it also would be a world with a greater number of opportunities to use force against an aggressor. Recall the law's proportionality requirement in the use of defensive force, which bars the use of disproportionate force. ${ }^{43}$ It is this limitation that holds back the paraplegic in the elevator from shooting the person kicking him. Especially as it is commonly formulated in the United States, the requirement has interesting implications for the use of non-lethal weapons: it significantly increases the frequency with which non-lethal force may lawfully be used.

Doctrine, 71 VA. L. REv. 1 (1985). Current law focuses on the person's culpability as to causing the justifying conditions. I would have it focus instead on the person's culpability at T1 of causing the prohibited result at T2. See id. at 27-50. However, the end result in the situation at hand would be the same: liability for causing the property destruction.

${ }^{43}$ See supra notes 13-14 and accompanying text. 


\section{A. Universal Versus Two-Category Proportionality Requirement}

Several countries and a few states have a proportionality requirement stated in general terms - what might be called a "universal" proportionality requirement - which permits the use of only that amount of defensive force proportionate to the harm threatened. ${ }^{44}$ In contrast, a majority of American jurisdictions follow the Model Penal Code, which has a more modest requirement - what might be called a "two-category" proportionality requirement. Instead of requiring a proportionate response across the continuum of possible threats, the Model Penal Code creates two categories, deadly force (which includes all firearms) ${ }^{45}$ and non-deadly force, and sets special proportionality limitations only on the use of deadly force. ${ }^{46}$ In other words, as long as a defender stays below the deadly force threshold, there is effectively no proportionality requirement.

Thus, when a defender shifts from carrying a firearm to carrying a nonlethal weapon, proportionality in response need no longer be a concern. No matter what the nature of the threat, the defender can do whatever is necessary to defend himself. The paraplegic in the elevator can shoot away with his nonlethal weapon if it is necessary to stop the kicking. All the complex

${ }^{44}$ See, e.g., IND. CODE ANN. $\S 35-41-3-2$ (West 2004) ("A person is justified in using reasonable force against another person to protect the person or a third person from what the person reasonably believes to be the imminent use of unlawful force. However, a person is justified in using deadly force only if he reasonably believes that that force is necessary to prevent serious bodily injury to the person or a third person or the commission of a forcible felony." (emphasis added)); IOWA CODE ANN. $§ 704.3$ (West 2003) ("A person is justified in the use of reasonable force when the person reasonably believes that such force is necessary to defend oneself or another from any imminent use of unlawful force." (emphasis added)); LA. REV. STAT. ANN. $\$ 14: 19$ (2007) ("The use of force or violence upon the person of another is justifiable when committed for the purpose of preventing a forcible offense against the person or a forcible offense or trespass against property in a person's lawful possession, provided that the force or violence used must be reasonable and apparently necessary to prevent such offense, and that this Section shall not apply where the force or violence results in a homicide." (emphasis added)); Strafgesetzbuch [StGB] [Penal Code] Nov. 13, 1988, Bundesgesetzblatt [BGBI] I, § 34, translated in MiCHAEL BOHLANDER, THE German Criminal Code: A Modern English Translation 44 (2008) (“A person who, faced with an imminent danger to life, limb, freedom, honor, property or another legal interest which cannot otherwise be averted, commits an act to avert the danger from himself or another, does not unlawfully, if, upon weighing the conflicting interests, in particular the affected legal interests and the degree of the danger facing them, the protected interest substantially outweighs the one interfered with.”); Penal Law, 5737-1977, § 34(K) (Isr.) (Aryeh Greenfield trans., 2d ed. 1994) (requiring immediate necessity to prevent imminent serious injury and no alternative available act to justify use of force in defense).

45 Model Penal Code $\S 3.11(1)$.

46 Compare id. $\$ 3.04(1)$ (permitting defensive force against any unlawful force), with id. $\S 3.04(2)$ (b) (limiting the use of deadly force only to protect against "death, serious bodily injury, kidnapping or sexual intercourse compelled by force or threat"). 
proportionality-based limitations on use of deadly force - such as the retreat and surrender of property rules, and the minimum threat requirements ${ }^{47}$ - just drop away.

One may wonder whether the two-category approach of self-defense so common in American law risks creating a culture of "cowboys" who will draw and fire whenever unjustifiably threatened or restrained. The proliferation of non-lethal weapons could open up a new Wild West future, a result unanticipated by many in the non-lethal weapon movement, but a result current law nonetheless would provide. The manufacturers of Tasers are not oblivious to this possibility and have taken steps to control non-lethal weapon use. For example, when the current generation of Tasers are fired, they deploy a flurry of small paper disks that bear the cartridge's serial number and would be difficult to retrieve quickly, ${ }^{48}$ making it easier for police to identify the user and his exact location.

\section{B. Cowboys and the Universal Proportionality Requirement}

The greater freedom-to-defend attribute of non-lethal weapons would continue to a large extent even if American law were changed from its current two-category approach to a universal-proportionality requirement. That is, if the law required a defender's use of force always be proportionate to the harm threatened, even when non-deadly defensive force is used, non-lethal weapons would still allow defensive action more frequently than would firearms. The defender using a non-lethal weapon could use defensive force as long as the extent of the threat was serious enough that his non-lethal weapon's amount of force was proportionate.

Given that Taser shocks are typically painful but have no lasting effect, they would clearly be a proportionate response to any threat of that same nature or greater, and presumably to some less serious threats. The proportionality requirement does not require that the force used always be strictly equal to or less than the force threatened. The wrongfulness of the attack weighs on the scale to favor the defender and to disfavor the attacker. ${ }^{49}$ Presumably, a defender can inflict greater pain to prevent an attack than the attack itself threatens, as long as the original attack is unlawful. It is this accounting for the wrongfulness of the attack that explains, for example, why lethal force is authorized to defend against a less-than-lethal threat under the two-category approach discussed above. ${ }^{50}$ Thus, the paraplegic in the elevator being kicked could probably use a Taser to prevent the kicks even under the universalproportionality requirement.

\footnotetext{
${ }^{47}$ See, e.g., id. $\$ \S 3.04(2)(\mathrm{b}), 3.06(3)(\mathrm{d})$.

${ }_{43}$ Wyant, supra note 33 , at 268.

49 See Robinson, supra note $10, \S 8.4$, at 443.

50 See Model Penal Code $\$ 3.04(2)$ (b).
} 
The foreseeable further advances in non-lethal weapon technology suggest that the situations in which current law will authorize defensive force will only increase. The opportunities for lawful use of force will be greatest with the weapon that offers the most flexibility in the amount of force it can employ. If a defender can "dial up" any increment of force, he can always use force to defend against a threat, even under the universal-proportionality requirement. Given the nature of the technology behind many of the new and developing non-lethal weapons - such as laser and microwave guns - it is quite likely that this kind of flexibility in the amount of defensive force available will be easy to obtain. Like Star Trek's Captain Kirk having his crew "set phasers to stun," the new non-lethal weapons can provide just the amount of force proportionate to the harm threatened.

\section{Cowboy Chaos or Full Vindication of Rights?}

Widespread availability of non-lethal weapons would essentially do away with proportionality limitations on the use of defensive force, but would this produce a Wild West culture of frequent use of force? Probably not. Remember that the proportionality requirement is not the only limitation on the use of force. A defender remains obliged to use force only when it is necessary. ${ }^{51}$ If the paraplegic can stop the kicking by politely asking the attacker to stop - or by apologizing for running over his foot - then his use of force of any kind is not "necessary" and will not be justified.

Would the increased opportunity provided by non-lethal weapons to use defensive force lawfully be a bad thing? There is little reason to think we would have more threats calling for defensive force than we have today. In fact, one might speculate that the number of threats might go down as the use of non-lethal weapons goes up. The potential victims' greater ability to lawfully defend themselves against all nature of threats might deter the threats in the first place, thereby reducing overall conflicts.

Importantly, a greater availability of non-lethal weapons will alter the permitted response to the existing aggression. Where the threat is lethal or serious, the greater availability of non-lethal weapons will avoid the use of a firearm and thereby reduce the chance the aggressor will be killed, a desirable result. Where the threat is non-lethal, the greater availability of non-lethal weapons will increase the likelihood the defender will succeed in defense without injury, but will also probably increase the chance defensive force will be used. But if one believes in the value of personal autonomy, as expressed in present defensive force rules, this too is a desirable result. It would seem more attractive than our present situation in which the stronger can intimidate the weaker, putting the latter in the unattractive position of either having to use a firearm unlawfully or do nothing. A world of non-lethal weapons can better protect personal autonomy while better limiting injury to aggressors.

\footnotetext{
${ }^{51}$ See supra notes 11-12 and accompanying text.
} 


\section{CONCLUSION}

Given the nearly universal requirement that defensive force be no more than necessary to defend, and given the increasing effectiveness and availability of less lethal weapons, the use of firearms in defense is increasingly unjustified. While some may worry that one's right to use defensive force is being eroded by the shift to non-lethal weapons that current law promotes, the real concern may be an era of too much use of defensive force rather than too little. The technical advances combined with current law might promote a culture of nonlethal weapon "cowboys," in which non-lethal force is authorized in situations where no force would be used today. On the other hand, the greater use of non-lethal force might provide the ideal balance in which the right to personal autonomy is promoted but the injury to law-breakers is minimized.

Whatever the future may bring, it seems clear today that Heller affirms only a right to bear a firearm, not the right to use it in defense. It is the criminal codes' rules of defensive force that will govern this right, not the Second Amendment. 